\title{
Interação entre alface e tomateiro consorciados em ambiente protegido, em diferentes épocas
}

\author{
Arthur Bernardes Cecílio Filho ${ }^{1 ; 4}$; Bráulio Luciano A Rezende ${ }^{5}$; José Carlos Barbosa ${ }^{5}$; Anderson Luiz \\ Feltrim5; Gilson S da Silva²; Leilson C Grangeiro $^{3}$ \\ ${ }^{1}$ FCAV-UNESP, Rodovia Prof. Paulo D. Castellane, s/n, 14884-900 Jaboticabal-SP; ${ }^{2}$ FCAV-UNESP, Depto. Ciências Exatas; ${ }^{3}$ UFERSA, \\ C. Postal 137, 59625-900 Mossoró-RN. ${ }^{4}$ Bolsista CNPq; ${ }^{5}$ FCAV-UNESP, Pós-graduandos em Agronomia, Produção Vegetal; \\ rutra@fcav.unesp.br, blrezende@ig.com.br, jcbarbosa@fcav.com.br, leilson@ufersa.edu.br
}

\section{RESUMO}

Dois experimentos foram conduzidos na UNESP, em Jaboticabal (SP), com o objetivo de avaliar a interação entre alface e tomateiro, em ambiente protegido. Consórcios estabelecidos por transplantes da alface aos $0 ; 10 ; 20$ e 30 dias após o transplante do tomateiro foram avaliados em dois períodos (abril a setembro/03 e janeiro a maio/04) e comparados às suas monoculturas, também estabelecidas nas mesmas épocas dos consórcios. Cada experimento foi conduzido em delineamento de blocos ao acaso, com nove tratamentos. Verificou-se que a produtividade do tomateiro e o percentual de frutos nas classes 50 e 60 não foram influenciados pela alface, independentemente da época em que esta foi transplantada. Por outro lado, a alface produziu menos em consórcio do que em monocultura, e quanto mais atrasado o seu transplante, em relação ao tomateiro, maior foi a redução em sua produtividade.

Palavras-chave: Lactuca sativa, Lycopersicon esculentum, sistemas de cultivo, consorciação de culturas.

\section{ABSTRACT}

Interaction between lettuce and tomato plants, in intercropping cultivation, established at different times, under protected cultivation

Two experiments were carried out in Jaboticabal, São Paulo State, Brazil, to evaluate the interaction between lettuce and tomato, in intercropping, in a protected cultivation. Lettuce plants were transplanted into a tomato field at $0 ; 10 ; 20$, and 30 days after tomato transplantation. These evaluations were performed from April to September 2003 and from January to June 2004. Both, lettuce and tomato crops, were also cultivated in monoculture in order to compare this system and the intercropping one. Each experiment was carried out in a randomized complete block design with nine treatments. Both tomato yield and fruit classification into grades were not influenced by lettuce crop independently of the transplantation time. On the other hand, lettuce, when intercropped, yielded lesser than when cultivated in sole crop and the yield decreased with the delaying transplanting date.

Keywords: Lactuca sativa, Lycopersicon esculentum, cropping systems, intercropped cultures.

(Recebido para publicação em 19 de novembro de 2006; aceito em 19 de março de 2008)

A tualmente, a preocupação do olericultor não pode restringir-se apenas à produtividade e à qualidade da produção almejada, mas também como ela será obtida. O modus operandi deve compreender o planejamento para promover a redução de custos para a produção das hortaliças e propiciar menor impacto ambiental. Os reflexos serão percebidos na maior competitividade do produto e do produtor no mercado, assim como na melhor sustentabilidade do sistema.

Nos últimos anos, grande foi o aumento na consideração das relações entre a agricultura e o meio ambiente, dos recursos naturais e da qualidade dos alimentos (Ehlers, 1999). Em tempos mais distantes, o crescimento da produção de alimentos se fez pela expansão da área; mais recentemente, por incremento na produtividade. Sem desconsiderar a importante contribuição dessas duas ferramentas, a consorciação de culturas pode contribuir direta e/ou indiretamente para o menor impacto ambiental, visto que entre suas vantagens pode proporcionar, segundo Hortwith (1985), redução do uso de insumos feitos a partir de fontes não renováveis, tais como defensivos agrícolas ou pelos menos permitir maior aproveitamento dos mesmos, e à maior rentabilidade do cultivo (Rezende et al., 2005b, 2005c).

Tomateiro e alface são hortaliças de grande expressão econômica na olericultura nacional, as quais em cultivo consorciado, sob ambiente protegido, atendem ao importante, e talvez primeiro critério para se obter sucesso em consórcios: serem contrastantes em características agrobotânicas, a fim de explorarem a complementaridade temporal e/ou espacial.
Além de Rezende et al. (2005a), que avaliaram o efeito de consórcio tomateiro e alface, com transplante desta de 0 a 42 dias após o transplante do tomateiro, não foram encontrados outros trabalhos na literatura científica nacional sobre a consorciação dessas duas hortaliças. Nos Estados Unidos, Jett et al. (2005) verificaram que a produtividade e classificação de frutos de tomate não foram influenciadas quando o tomateiro foi transplantado no mesmo dia do transplante da alface. Segundo Debarba (2000), citado por Souza \& Resende (2003), a alface é uma cultura beneficiada pela associação ao tomateiro. Por outro lado, o mesmo autor não informa se há, e qual é o tipo de efeito da alface no tomateiro.

Diante do exposto, dois experimentos foram conduzidos, em casa de vegetação, com o objetivo de avaliar a 
interação entre a alface e tomateiro em cultivo consorciado, comparado ao solteiro, por meio de comparações de suas produtividades e características comerciais das hortaliças.

\section{MATERIAL E MÉTODOS}

Os dois experimentos foram conduzidos de 17/04 a 09/09/03 e de 30/01 a 27/05/04, em casa de vegetação de 614,4 $\mathrm{m}^{2}$, de modelo teto em arco, com pédireito de $3 \mathrm{~m}$, coberta com filme de polietileno de baixa densidade, transparente, de $150 \mathrm{~mm}$ de espessura, aditivado contra raios ultravioleta, localizada na UNESP, Campus de Jaboticabal, situada à altitude de 575 metros, latitude $21^{\circ} 15^{\prime} 22^{\prime \prime S}$ e longitude $48^{\circ} 15^{\prime} 58^{\prime \prime}$ W. O clima de Jaboticabal é classificado como subtropical com chuvas de verão, e inverno relativamente seco. Apresenta médias anuais de $1.424,6 \mathrm{~mm}, 22,2^{\circ} \mathrm{C}, 28,9^{\circ} \mathrm{C}$ e $16,8^{\circ} \mathrm{C}$, respectivamente, para precipitação pluvial e temperaturas média, máxima e mínima (Resenha..., 2005). No cultivo de 17/04 a 09/09/03, as temperaturas médias das máximas, mínimas e médias mensais foram 28,$8 ; 14,3$ e $20,7^{\circ} \mathrm{C}$, respectivamente, enquanto no segundo cultivo, 30/01 a 27/05/04, os valores médios foram 29,$2 ; 18$ e $22,5^{\circ} \mathrm{C}$.

O solo da área, segundo classificação de Andrioli \& Centurion (1999), corresponde ao Latossolo Vermelho Eutroférrico típico de textura muita argilosa, A moderado caulinítico-oxídico, relevo suave ondulado a ondulado.

O tomateiro foi a cultura principal. A alface, secundária, foi transplantada aos $0 ; 10 ; 20$ e 30 dias após o transplante (DAT) do tomateiro, correspondendo aos quatro consórcios. Para cada época de estabelecimento do consórcio, também, foi instalado um cultivo solteiro de alface. Aos oito tratamentos somase o cultivo solteiro do tomateiro, totalizando nove tratamentos. Os experimentos 1 e 2 , sob delineamento de blocos ao acaso, tiveram, respectivamente, oito e cinco repetições. As unidades experimentais foram constituídas por dez plantas de tomateiro e 40 plantas de alface, distribuídas, respectivamente em duas e quatro linhas de plantas. As fileiras duplas do tomateiro ficaram centra-

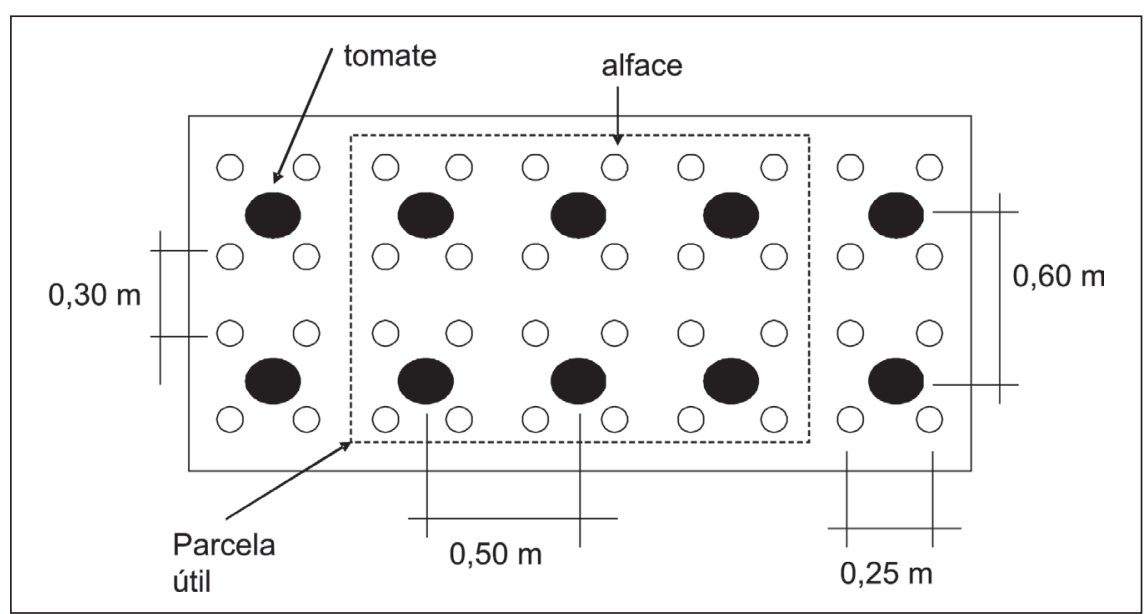

Figura 1. Representação gráfica de uma parcela, da área útil para coleta de dados e disposição das culturas em consórcio, tomate (fileira dupla - $1,20 \times 0,60 \times 0,50 \mathrm{~m})$ e alface $(0,30 \mathrm{x}$ $0,25 \mathrm{~m}$ ). (graphic representation of a experimental unit, of the useful area for collection of data and disposition of the cultures in intercropping, tomato (double spacing $-1.20 \mathrm{x} 0.60 \mathrm{x}$ $0.50 \mathrm{~m})$ and lettuce $(0.30 \times 0.25 \mathrm{~m})$ ). Jaboticabal, UNESP, 2003/2004.

lizadas no canteiro, distando entre as fileiras simples em $0,60 \mathrm{~m}$, e constando de duas fileiras de alface entre as fileiras duplas do tomateiro e duas linhas externas à mesma. As características do tomateiro e da alface foram avaliadas, respectivamente, nas seis e 20 plantas centrais (Figura 1).

O preparo do solo, para os dois experimentos, foi feito com aração, gradagem e posterior confecção dos canteiros. As análises químicas do solo do primeiro e segundo cultivos, na camada de $0-20 \mathrm{~cm}$, apresentaram, respectivamente: $\mathrm{pH}_{(\mathrm{CaCl} 2)}$ de 5,7 e 5,8; 22 e $18 \mathrm{~g} \mathrm{dm}^{-3}$ de matéria orgânica, 138 e $67 \mathrm{mg} \mathrm{dm}^{-3}$ de $\mathrm{P}_{\text {(resina) }}$. Em mmol $_{\mathrm{c}} \mathrm{dm}^{-3}$, os solos continham 2,4 e 1,2 de $\mathrm{K} ; 51$ e 32 de $\mathrm{Ca} ; 21$ e 8 de $\mathrm{Mg}$ e $77 \%$ e $60 \%$ de saturação de bases. Com base nas análises de solo, fez-se a calagem, 30 dias antes da instalação do experimento 2, utilizando-se de calcário calcinado de PRNT $122 \%$, objetivando elevar a saturação por bases do solo a $80 \%$. As adubações de plantio dos consórcios e monocultura do tomateiro receberam doses de P (superfosfato simples) e K (cloreto de potássio) conforme recomendação de Trani et al. (1997a) para a cultura do tomateiro. Quanto ao N, aplicaram-se $60 \mathrm{~kg} \mathrm{ha}^{-1}$, na forma de nitrato de amônio. As adubações de cobertura para as culturas foram feitas conforme recomendação de Trani et al. (1997a, 1997b).

Foi utilizada, para a cultura do tomateiro (Lycopersicon esculentum), a cv. Débora Max, e, na cultura da alface (Lactuca sativa), a cv. Vera. As mudas do tomateiro e alface foram formadas, respectivamente, em bandejas para 128 e 288 células. A alface foi transplantada com quatro folhas após as cotiledonares, em espaçamento de $0,30 \mathrm{~m}$ entre linhas e 0,25 m entre plantas na linha. O tomateiro foi transplantado, também, com quatro folhas após as cotiledonares, em espaçamento de 1,20 m entre linhas duplas x 0,60 m entre linhas simples x 0,50 $\mathrm{m}$ entre plantas na linha.

Nos dois períodos de cultivo, o tomateiro foi conduzido com duas hastes. O número de cachos conduzidos foi diferente entre as épocas. Na primeira época, eliminou-se o meristema apical após a sétima inflorescência da haste principal; na segunda época, devido ao severo ataque de traça do tomateiro (Tuta absoluta), fato que encurtou o ciclo, somente foram aproveitados os primeiros quatro ou cinco cachos de cada haste. $\mathrm{Na}$ fase inicial das culturas até cerca de 25 DAT da alface, para ambas as culturas foram pulverizações semanais para controle de tripes e pulgão. Para o controle de pragas do tomateiro, especialmente, brocas de fruto e traça, as pulverizações dirigiram-se às partes mediana e apical do tomateiro, não atingindo a alface. O tutoramento das plantas foi feito com fitilhos plásticos no sentido vertical, envolvendo cada uma das hastes do tomateiro. O fitilho foi 


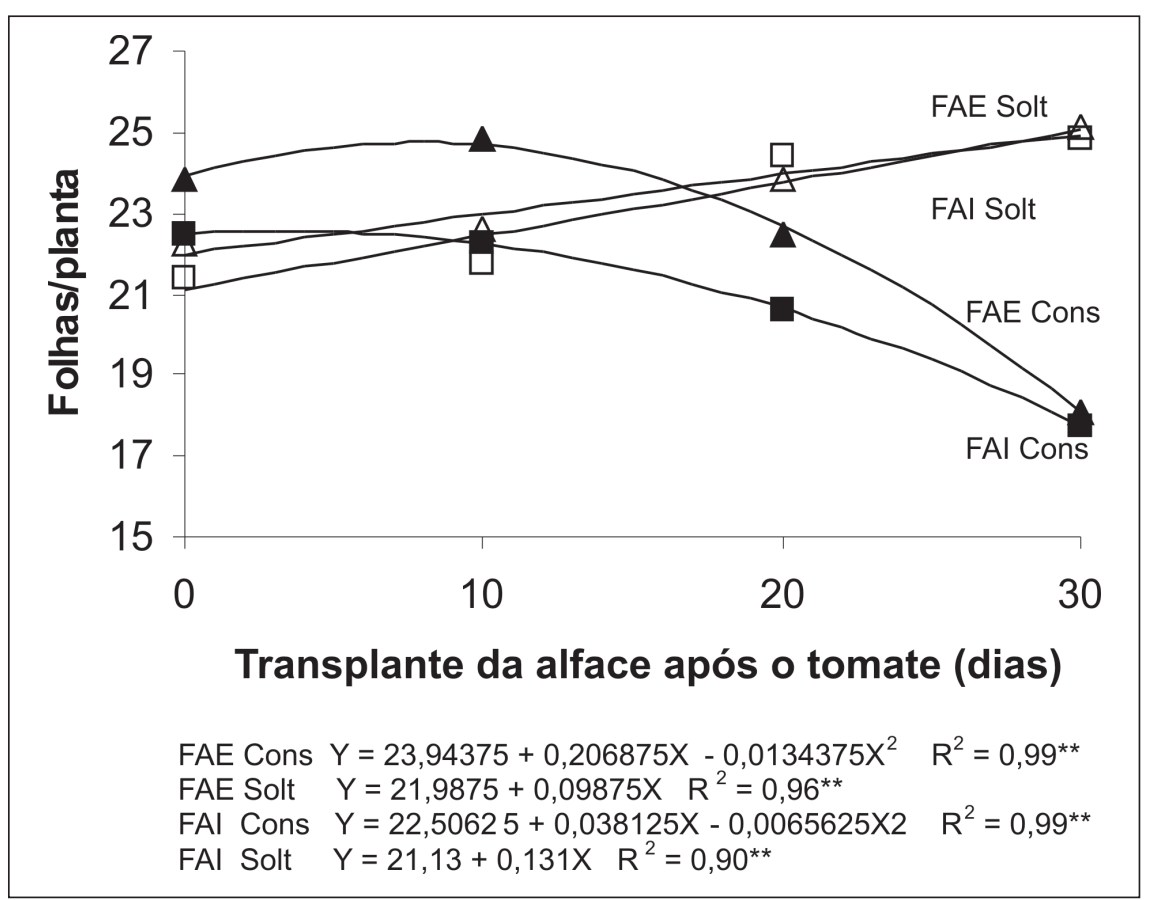

Figura 2. Número de folhas de alfaces localizadas em linhas externas (FAE) e internas (FAI) do canteiro, em cultivos consorciados (Cons) e solteiro (Solt), em função da sua época de transplante após o transplante do tomateiro. Primeiro cultivo: 17/04 a 09/09/03. (number of lettuce leaves located on external (FAE) and internal (FAI) lines of the stonemason, in associated (Cons) and single (Solt) cultivation, depending on the transplanting date after the transplant of the tomato. First cultivation: 04/17 to 09/09/03). Jaboticabal, UNESP, 2003/2004.

amarrado a arames dispostos paralelamente ao terreno, situados rente ao solo e a $2 \mathrm{~m}$ de altura.

As colheitas de alface de cultivos solteiros foram realizadas nas mesmas datas dos respectivos consórcios. Para os transplantes efetuados em 17/04, 27/ $04,07 / 05$ e 17/05/03, as colheitas ocorreram respectivamente em 02/06, 17/06, $27 / 06$ e 08/07/03. No segundo cultivo, para os transplantes de 30/01,09/02, 19/ 02 e 01/03/04, as colheitas se deram em $13 / 03,19 / 03,29 / 03$ e 15/04/04. As colheitas de tomateiro, para o primeiro cultivo, encerraram-se em 09/09/03; e em 27/05/04 no segundo cultivo.

Para alface, foram avaliados o número de folhas, diâmetro e matéria fresca da parte aérea, separadamente para plantas localizadas em linhas externas e internas do canteiro, e avaliação visual de aspectos comerciais da alface (coloração e sinais de pendoamento e estiolamento). Para o tomateiro, foram avaliadas a produção comercial de frutos de tomateiro (kg planta-1), adotando-se a classificação sugerida por Companhia... (2003). Foram considerados comerciais os frutos com diâmetro igual rio, ateve-se à análise de variância conjunta. O teste de Tukey foi utilizado para diferenciar as médias obtidas para as características de tomateiro e alface influenciadas pelo período de cultivo e sistemas de cultivo. Para a época de transplante, as médias foram ajustadas à regressão polinomial.

\section{RESULTADOS E DISCUSSÃO}

Conforme a análise conjunta dos experimentos, a produtividade da cultura do tomateiro e a produção de frutos nas classes 50 e 60 não foram significativamente afetadas pelos tratamentos $(p>0,05)$. A interação períodos e tratamentos não foi significativa $(p>0,05)$ sobre as características. A produtividade do tomateiro, nos sistemas de cultivo avaliados, variou de 7,6 a 8,2 kg planta ${ }^{-1}$. Os percentuais de frutos obtidos nos tratamentos (consórcios e monocultura) variaram de 49,9 a $59,1 \%$ na classe 50 e de 40,3 a $48,3 \%$, na classe 60 , sem haver diferença significativa entre os mesmos.

Rezende et al. (2005a), avaliando consórcios estabelecidos com o transplante da alface aos $0 ; 14 ; 28$ e 42 DAT do tomateiro, também constataram que a presença da alface não influenciou, positiva ou negativamente, a cultura do tomateiro, bem como a percentagem da produção de frutos nas classes 50 e 60. Jett et al. (2005), avaliando consórcios de tomateiro e alface, em cultivo sob túnel alto, verificaram que o início do período de colheita, a produtividade e a classificação do tomateiro, não foram influenciadas quando o consórcio foi estabelecido com o transplante do tomateiro no mesmo dia da semeadura da alface.

Maior influência da alface sobre o tomateiro era esperada quando as duas culturas foram transplantadas no mesmo dia. Contudo, devido ao crescimento inicial muito lento da alface comparativamente ao do tomateiro e, também, por predominar naquela hortaliça o crescimento horizontal em relação ao vertical do tomateiro, pode-se considerar que as culturas ocuparam nichos diferentes. Hart (1986) afirma que, a fim de coexistirem e, consequentemente, apresentarem fraca competição interespecífica, as espécies devem possuir nichos sufi- 
cientemente distintos e os recursos demandados não podem ser idênticos.

Essa condição de nichos diferenciados pode ser retratada parcialmente pelas características botânicas e agronômicas das espécies estudadas, as quais são importantes na determinação do grau de complementaridade entre as mesmas para uso dos recursos do ambiente e composição de suas produtividades (Trenbath, 1976, 1986; Barker \& Francis, 1986).

Observou-se, nos dois experimentos, que a alface, por ocasião de dois terços de seu período de crescimento pós-transplante, apresentava cerca de 10 a 12 folhas e diâmetro aproximado de $20 \mathrm{~cm}$; portanto, não tendo contato com as plantas de tomateiro. Rezende et al. (2005a) também justificaram a ausência de influência da alface sobre o tomateiro em decorrência de diferenças observadas entre as espécies, tais como arquitetura, porte, velocidade de crescimento e ocupação do terreno.

Há de ser ressaltado que as diferenças entre alface e o tomateiro, apontadas na literatura e consideradas neste trabalho como responsáveis pela ausência de interferência de um sobre o outro, estão bastante relacionadas à utilização, pelas espécies consorciadas, do recurso luz. Este é apontado por Beets (1982) e Sinoquet \& Caldwell (1995) como o principal fator limitante ao crescimento e produção de culturas em consórcio, uma vez satisfeitas as necessidades de água e nutrientes. Devido ao seu rápido crescimento em relação à alface e distribuição de seu dossel fotossintético acima do extrato ocupado pela alface, o tomateiro não sofreu redução na interceptação da radiação incidente quando em consórcio, em relação ao cultivo solteiro.

Diferença significativa foi constatada entre os experimentos (períodos de cultivo) para a produtividade do tomateiro $(\mathrm{p}<0,01)$ e percentuais da produção nas classes 50 e 60 ( $\mathrm{p}<0,01)$. Maior produtividade $\left(9,1 \mathrm{~kg} \mathrm{planta}^{-1}\right)$ foi obtida no cultivo de abril a setembro de 2003, enquanto no cultivo de janeiro a maio de 2004 obtiveram-se 6,2 kg plan$\mathrm{ta}^{-1}$. No primeiro cultivo a produtividade foi elevada, correspondendo às expectativas de produção dos híbridos atuais,

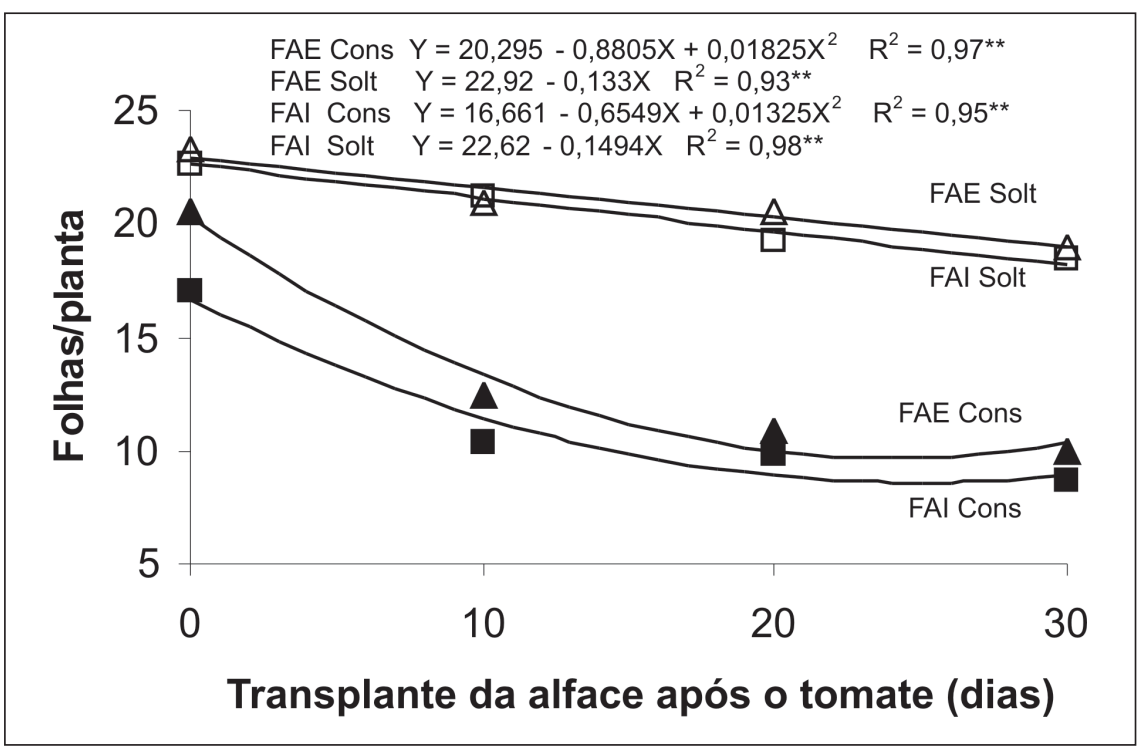

Figura 3. Número de folhas de alfaces localizadas em linhas externas (FAE) e internas (FAI) do canteiro, em cultivos consorciado (Cons) e solteiro (Solt), em função da sua época de transplante após o transplante do tomateiro. Segundo cultivo: 30/01 a 27/05/04. (number of lettuce leaves of plants located on external (FAE) and internal (FAI) lines of the stonemason, in associated (Cons) and single (Solt) cultivations, depending on the transplanting date after the tomato transplant. Second cultivation: 01/30 to 05/27/04). Jaboticabal, UNESP, 2003/2004.

cultivados em ambiente protegido, com período de colheita de dois meses. Este rendimento comercial correspondeu a $20,1 \mathrm{~kg} \mathrm{~m}^{-2}$, ou seja, $201.460 \mathrm{~kg} \mathrm{ha}^{-1}$, superior em $45,5 \%$ à produtividade do segundo cultivo $\left(13,8 \mathrm{~kg} \mathrm{~m}^{-2}\right), 138.528$ $\mathrm{kg} \mathrm{ha}^{-1}$. A grande redução na produtividade de tomateiro do segundo cultivo foi devida ao severo ataque de traça, Tuta absoluta, que foi determinante na formação de menor dossel fotossintético e, conseqüentemente, favoreceu a redução do número de frutos colhidos. Em plantas do segundo cultivo foram colhidos sete ou oito cachos por planta, enquanto, na primeira época, foram $11 \mathrm{ou}$ 12 cachos.

Assim como verificado para produtividade, no primeiro cultivo, obteve-se maior produção comercial de frutos na classe $60(48,6 \%)$. No cultivo de janeiro a maio, obtiveram-se $35,4 \%$ de frutos nesta classe, ou seja, cerca de $30 \%$ menos que no primeiro cultivo. Na classe 50 , a produção total de frutos para o primeiro e segundo cultivos foram respectivamente, de $48,7 \%$ e $64,6 \%$. A predominância de frutos em classes comerciais superiores ou inferiores depende, em suma, de quão satisfeito foi o potencial produtivo da cultivar, resultantes de estímulos e estresses do ambiente e de ações do homem. Assim, o maior percentual de distribuição de frutos na classe 60 obtido no primeiro cultivo, em que também se constatou maior produtividade, pode ser atribuído à melhor relação fonte/dreno da planta de tomateiro naquele período do que no segundo.

Para alface, segundo a análise conjunta dos experimentos, houve efeito significativo $(\mathrm{p}<0,01)$ somente dos tratamentos no diâmetro de alfaces (DE) localizadas nas linhas externas do canteiro (DE). O desdobramento dos tratamentos, constituídos pela interação dos fatores sistemas de cultivo (solteiro e consórcio) e épocas de transplante da alface em relação ao do tomateiro, permitiu constatar que houve interação significativa dos fatores períodos de cultivo e sistemas de cultivo $(\mathrm{P}<0,05)$ e para o fator época de transplante da alface $(\mathrm{p}<0,01)$ no $\mathrm{DE}$, fato que determinou a avaliação dos fatores em cada período de cultivo.

No primeiro cultivo, o DE foi significativamente influenciado pelos fatores sistema de cultivo $(\mathrm{p}<0,01)$ e época de transplante da alface $(\mathrm{p}<0,01)$, sem haver interação dos mesmos. O cultivo solteiro proporcionou plantas com diâmetro maior $(32,8 \mathrm{~cm})$ do que em consórcio $(30,9 \mathrm{~cm})$. Quanto ao efeito da 


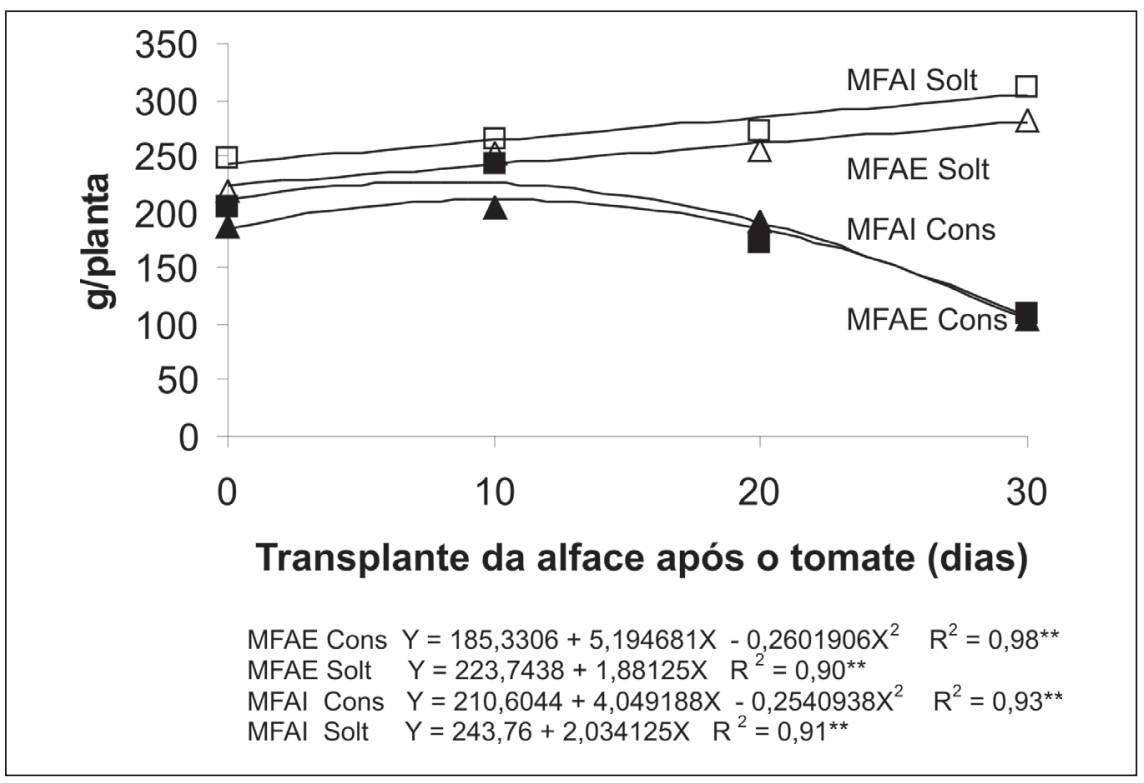

Figura 4. Massa da matéria fresca de alface localizada nas linhas externas (MFAE) e internas (MFAI) do canteiro, em cultivos consorciado (Cons) e solteiro (Solt), em função da época de transplante da alface após o transplante do tomateiro. Primeiro cultivo: 17/4 a 9/9/ 2003. (Mass of the fresh matter of located lettuce in the external lines (MFAE) and intern (MFAI) of the stonemason, in cultivations associated (Cons) and single (Solt), in function of the time of transplant of the lettuce after the transplant of the tomato. First cultivation: 4/17 to 9/9/2003). Jaboticabal, UNESP, 2003/2004.

época de transplante, maior DE $(33,2$ $\mathrm{cm})$ foi obtido quando a alface foi transplantada aos 12 DAT do tomateiro $(\mathrm{Y}=$ $31,7664+0,2327062 X-0,00955312 X^{2}$ $\left.\mathrm{R}^{2}=0,86^{* *}\right)$. No segundo período, o DE não foi influenciado significativamente ( $>0,05)$ pelos fatores avaliados e apresentou média de $32,5 \mathrm{~cm}$.

Para DI, houve interação significativa $(\mathrm{p}<0,01)$ para períodos e tratamentos. $\mathrm{Na}$ análise de variância para cada período, constatou-se interação significativa dos fatores no cultivo de abril a setembro/03. O cultivo de alface em consórcio com o tomateiro, quando as duas hortaliças foram transplantadas no mesmo dia, não promoveu diferença significativa no DI em relação à alface cultivada em sistema de monocultura. Contudo, quando foi transplantada com atraso superior a 10 DAT do tomateiro, a alface apresentou menores diâmetros da parte aérea em cultivo consorciado do que em monocultura. A diferença entre os sistemas de cultivo, a favor do cultivo solteiro, que era de $0,3 \mathrm{~cm}$ (não significativo) quando transplantados na mesma época, aumentou para 2,5; 5,3 e $5,7 \mathrm{~cm}$, respectivamente, quando se transplantou a alface aos 10; 20 e 30 dias após o transplante do tomateiro. Portanto, as reduções ocorridas em cultivo consorciado ( $\mathrm{Y}=33,215$ - 0,246625X $\mathrm{R}^{2}=0,74 * *$ ) foram maiores do que aquelas observadas na monocultura $(\mathrm{Y}=33,53438+0,1428125 \mathrm{X}-$ $\left.0,00703125 X^{2} \quad R^{2}=0,61 *\right)$. Quando a alface foi transplantada aos 30 DAT do tomateiro, o diâmetro $(25,8 \mathrm{~cm})$ representou $78 \%$ do diâmetro máximo obtido em consórcio a 0 DAT, enquanto, em cultivo solteiro, o diâmetro da alface transplantada aos 30 DAT correspondeu a $92 \%$. Portanto, além do efeito da época constata-se que houve competição interespecífica.

Para número de folhas de alface, também constatou-se interação significativa $(\mathrm{p}<0,01)$ entre período de cultivo e tratamentos. No primeiro cultivo, as respostas da alface quanto ao número de folhas por planta localizada em linhas externas (FAE) e internas (FAI) do canteiro foram semelhantes. Em cultivo solteiro, o FAE e o FAI aumentaram linearmente à medida que mais tardio foi o transplante da alface, evidenciando melhores condições ambientais para a alface. Por outro lado, em consórcio, o FAE e o FAI foram maximizados, respectivamente aos 8 e 4 DAT. Transplantes posteriores promoveram reduções em ambos (Figura 2), que aos 30 DAT foram de $27 \%$ e $21,4 \%$, respectivamente para o FAE e FAI, denotando o quanto prejudicial foi o sombreamento.

No segundo período de cultivo, 30/ 01 a 27/05/04, o DI não foi influenciado $(p>0,05)$ pelos fatores sistemas de cultivo e épocas de transplante da alface isoladamente, ou pela interação desses. O DI médio observado foi de 31,5 $\mathrm{cm}$. Contudo, semelhantemente ao observado no primeiro cultivo, no segundo período também se constatou interação significativa dos fatores sobre FAE $(p<0,01)$ e FAI $(p<0,05)$.

Para ambos os sistemas de cultivo, o número de folhas por planta de alface foi decrescente à medida que mais tardio foi o transplante desta em relação ao do tomateiro. Contudo, a intensidade de redução foi muito maior em cultivo consorciado do que em monocultura (Figura 3). Enquanto as reduções no FAE e FAI de alfaces em cultivo solteiro foram, respectivamente, de 17,8 e $20 \%$, entre os transplantes de alface realizados com 0 e 30 dias após o tomateiro; em consórcio, as reduções percebidas no FAE e FAI alcançaram, respectivamente, 49 e $50 \%$. Portanto, além de as condições ambientais atuarem desfavoravelmente sobre o número de folhas por planta, conforme se observou no cultivo solteiro, a competição interespecífica presente no cultivo consorciado contribuiu de modo marcante para a redução do número de folhas da alface.

Para massa da matéria fresca de alfaces localizadas em linhas externas (MFAE) e internas (MFAI) do canteiro, observou-se interação significativa dos fatores períodos de cultivo e tratamentos $(\mathrm{p}<0,01)$. No primeiro cultivo, verificou-se interação significativa dos fatores sistemas de cultivo e épocas de transplante da alface para ambas as características. Mesmo desempenho, dentro de cada sistema de cultivo, foi observado para MFAE e MFAI. Em condições de monocultura, as MFAE e MFAI aumentaram linearmente com o atraso no transplante da alface (Figura 4).

Os incrementos constatados tanto para MFAE quanto para MFAI de plan- 
tas de alface em cultivo solteiro, entre os transplantes realizados aos 0 e 30 DAT do tomateiro, foram de $25 \%$. Por outro lado, em consórcio, houve aumento da MFAE e MFAI com o atraso do transplante da alface até 10 e 8 DAT do tomateiro, 211,3 e 226,7 $\mathrm{g} \mathrm{planta}^{-1}$, respectivamente. A partir daí, menores massas foram obtidas, atingindo-se, aos 30 DAT do tomateiro, reduções de 49,4 e $54,4 \%$ na MFAE e na MFAI.

No segundo cultivo, verificou-se efeito significativo dos fatores sistemas de cultivo e épocas de transplante da alface para MFAE e MFAI. A interação dos fatores não foi observada ( $p>0,05)$. Tanto para o cultivo consorciado quanto para o solteiro, o atraso no transplante da alface em relação ao tomateiro proporcionou menores MFAE e MFAI (Figura 5). Entre os sistemas de cultivo, maior MFAE (173,1 g/planta) e MFAI $(169,8 \mathrm{~g} /$ planta) foram obtidas em monocultura, enquanto em consórcio obteve-se 62,3 e 55,1 g/planta, respectivamente para MFAE e MFAI. Este resultado está em concordância com os observados por Rezende et al. (2005a). Menores diferenças entre os sistemas de cultivo foram observadas para alface transplantada a 0 DAT do tomateiro. À medida que mais tardio se fez o estabelecimento do consórcio (transplante de alface em dias após o do tomateiro), maiores foram as reduções nas MFAE e MFAI. Rezende et al. (2005a) observaram, para cultivo de junho a novembro, que a MFAE e MFAI reduziram em até 86 e $91 \%$, respectivamente, do obtido com os transplantes de tomateiro e alface no mesmo dia.

Os resultados observados neste trabalho para massa de matéria fresca de alface consorciadas com tomateiro, refletiram as reduções no diâmetro e número de folhas de alfaces ocorridas no mesmo sistema de cultivo. A redução verificada na produção da alface em consórcio, com transplante da alface aos 30 DAT do tomateiro, foi acompanhada de perda de qualidade no aspecto comercial. As alfaces estioladas, com folhas de limbo alongado e fino foram observadas. Altas temperaturas do ar combinadas com baixos valores de radiação são prejudiciais às culturas, porque diminuem a fotossíntese, mantém eleva-

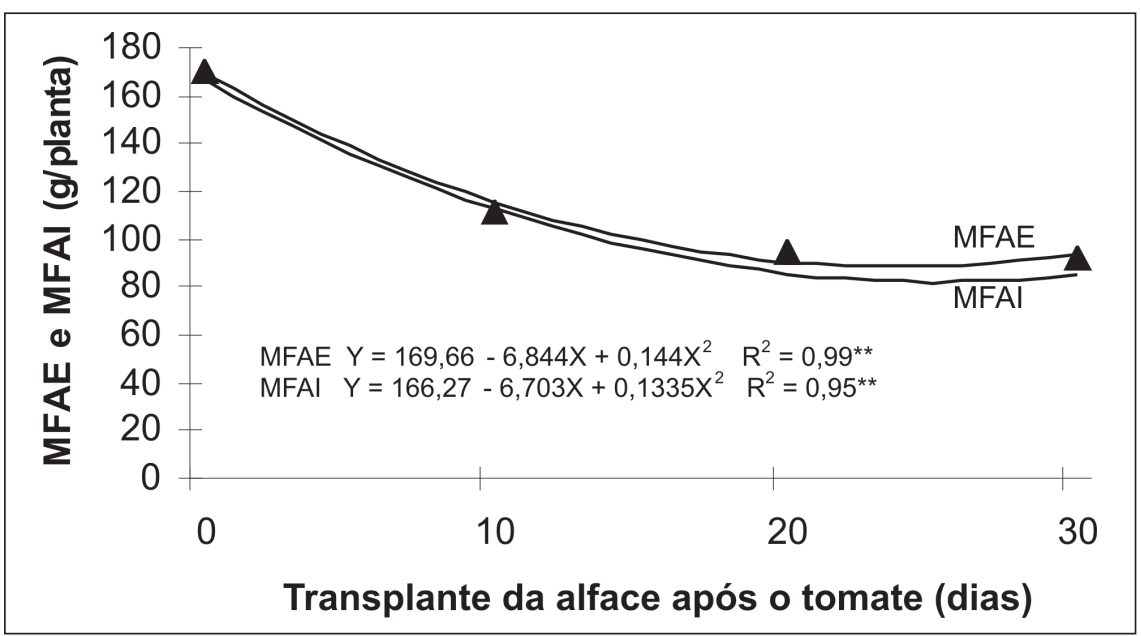

Figura 5. Massa da matéria fresca de alface localizada nas linhas externas (MFAE) e internas (MFAI) do canteiro, em função da época de transplante da alface após o transplante do tomateiro. Segundo cultivo: 30/01 a 27/05/04. (fresh matter mass of lettuce plants located in the external (MFAE) and internal (MFAI) lines of the stonemason, depending on the transplanting date of the lettuce after the transplant of the tomato plants. Second cultivation: 01/30 to 05/27/04). Jaboticabal, UNESP, 2003/2004.

da a respiração e modificam o balanço hormonal, favorecendo o estiolamento das plantas (Andriolo, 2000). A mais óbvia modificação de ambiente em um consórcio é onde a cultura de baixo porte se encontra sombreada pela de maior porte. Em consequiência, reduz a captação de radiação fotossinteticamente ativa pela cultura sombreada, resultando em menor crescimento e produtividade (Chui \& Shibles, 1984). Geralmente, folhas que crescem sob baixa luminosidade, são finas, apresentam aumento da área foliar e orientação mais horizontal (Hawkins, 1982).

Os resultados observados também foram constatados por Rezende et al. (2005a), quando se fez o transplante de alface 42 DAT do tomateiro. Puiatti et al. (2000) também constataram estiolamento dos pecíolos de taro (Colocasia esculenta) quando associados ao milho-doce em comparação às alturas observadas em plantas de cultivo solteiro. Os autores verificaram que houve redução da produtividade de taro e da produção de rizomas nas diferentes classes quando esta hortaliça foi consorciada com o milho, independentemente da combinação entre as componentes do consórcio. Atribuíram à essa influência negativa, a redução na área foliar por necrose das folhas das plantas de taro, que se encontravam sombreadas pelo milho e foram, logo após a colheita deste, expostas ao sol.

Portanto, de acordo com os resultados observados, o tomateiro prejudicou a alface e este prejuízo foi tanto maior quanto mais tardio foi o transplante da alface em relação ao tomateiro. A princípio, este resultado parece contrariar Debarba (2000) citado por Souza \& Resende (2003), o qual afirma que a alface se beneficia do consórcio com tomateiro. Sem discordar do autor, acredita-se que, sob determinadas condições, a alface pode beneficiar-se da presença do tomateiro, como, por exemplo, em condições de elevadas radiação e temperatura, acima de valores adequados à cultura, conforme observaram Midmore et al. (1988 a,b) na cultura da batata. De acordo com Allen et al. (1976), o sombreamento parcial pode proteger plantas de estresse hídrico e incrementar o uso eficiente da radiação incidente e fotossíntese (Willey, 1979; Harris et al., 1987).

Atribui-se aos resultados observados a baixa complementaridade referente ao aproveitamento da radiação incidente. Estes resultados estão de acordo com Midmore (1993), os quais informam que a alteração na época de plantio de uma das culturas e, portanto, no estabelecimento do consórcio, modifica o período de complementaridade e competição das culturas em consorciação, com reflexo na produtividade. 
As complementaridades espacial e temporal responsáveis pela maior eficiência de luz pelo cultivo consorciado do que aquela apresentada pela cultura solteira foram percebidas quando as espécies foram transplantadas em conjunto, haja vista a massa da matéria fresca apresentada pelas alfaces nessa condição de consórcio ser muito próxima à de cultivo solteiro. No entanto, as complementaridades foram sendo reduzidas à medida que aumentou o período entre o transplante do tomateiro e da alface. Como conseqüência, o maior porte do tomateiro com a ocupação de espaço superior ao da alface comprometeu o aproveitamento da radiação pela alface. Muitos autores citados por Sinoquet \& Caldwell (1995) concordam que a divisão da radiação entre as culturas componentes do consórcio é primeiramente estabelecida ou influenciada pela dominância vertical, com menor importância para a orientação das linhas de plantio e do ângulo da folha para a interceptação da radiação. Assim, a competição por luz é aumentada quando uma espécie atinge maior altura que a outra espécie associada. As espécies mais altas em um consórcio beneficiamse por terem folhas num extrato superior à de sua concorrente, onde intensidades luminosas são mais elevadas e onde não se presencia sombreamento interespecífico.

\section{AGRADECIMENTOS}

Os autores agradecem às agências de fomento à pesquisa CAPES, CNPq e FAPESP, pela concessão de recursos financeiros à pesquisa e auxílio-bolsa.

\section{REFERÊNCIAS}

ALLEN LH; SINCLAIR TR; LEMON ER. 1976. Radiation and microclimate relationships in multiple cropping systems. In: PAPENDICK PA; SANCHEZ PA; TRIPLETT EB. (Ed.). Multiple cropping. Madison: ASA. p. 171-200. (Special Publications)
ANDRIOLII; CENTURION JF. 1999. Levantamento detalhado dos solos da Faculdade de Ciências Agrárias e Veterinárias de Jabuticabal. In: CONGRESSO BRASILEIRO DE CIÊNCIADO SOLO, 27 . Anais... Brasília, SBCS (CD-ROM).

ANDRIOLO JL. 2000. Fisiologia da produção de hortaliças em ambiente protegido. Horticultura Brasileira 18: 26-33 (Suplemento)

BARKER TC; FRANCIS CA. 1986. Agronomy of multiple cropping systems. In: FRANCIS CA. Multiple cropping systems. New York: Macmillan Publishing Company. p. 161-182.

BEETS WC. 1982. Multiple cropping and tropical farming systems. Boulder: Westview Press. $155 \mathrm{p}$.

CHUI JAN; SHIBLES RM. 1984. Influence of spatial arrangements of maize on performance of an associated soybean intercrop. Field Crops Research 8: 187-198.

COMPANHIA DE ENTREPOSTOS DE ARMAZÉNS GERAIS DE SÃO PAULO. CEAGESP. 2003. Secretaria de Agricultura e Abastecimento. Centro de qualidade em horticultura. Programa Paulista para a melhoria dos padrões comerciais e embalagens de hortigranjeiros. Normas de classificação do tomateiro. São Paulo (Documentos, 25).

EHLERS E. 1999. Agricultura sustentável: origens e perspectivas de um novo paradgma. Guaíba: Agropecuária. 157p.

HART RD. 1986. Ecological: framework for multiple cropping research. In: FRANCIS CA. (Ed.). Multiple cropping systems. New York: Macmillan Publishing Company. p. 40-55.

HARRIS D; NATARAJAN M; WILLEY RW. 1987. Physiological basis for yield advantage in a sorghum/groundnut intercrop exposed to drought. I. Dry matther production, yield and light interception. Field Crops Research 17: 259-272.

HAWKINS AF. 1982. Light interception, photosynthesis and crop productivity. Outlook Agriculture 11:104-113.

HORWITH B. 1985. A role for intercropping in modern agriculture. BioScience 35: 286-291.

JETT LW; CHISM JS; CONLEY SP. 2005, 15 de setembro. Intercropping systems for tomatoes within a high tunnel. Disponível em http:// www.hightunnels.org/images/Assets.

MIDMORE DJ. 1993. Agronomic modification of resource use and intercrop productivity. Field Crops Research 34: 357-380.

MIDMORE DJ; BERRIOS D; ROCA J. 1988a. Potato (Solanum spp.) in the hot tropics. V. Intercropping with maize and the influence of shade on tuber yields. Field Crops Research 18: 159-176.

MIDMORE DJ; ROCA J; BERRIOS D. 1988 b. Potato (Solanum spp.) in the hot tropics. IV. Intercropping with maize and the influence of shade on potato microenvironment and crop growth. Field Crops Research 18:141-157.
PUIATTI M; FÁVERO C; FINGER FL; GOMES JM. 2000. Crescimento e produtividade de inhame e de milho doce em cultivo associado. Horticultura Brasileira 18: 24-30.

Resenha meteorológica do período 1971-2000. 2005, 10 de setembro. Disponível em http:// www.fcav.unesp.br/departamentos/ cienciasexatas/caract/estacao/ resenha71_00.htm.

REZENDE BLA; CANATO GHD; CECÍLIO FILHO AB. 2005a. Influência das épocas de cultivo e do estabelecimento do consórcio na produção de tomateiro e alface consorciado. Ciência e Agrotecnologia 29: 77-83.

REZENDE BLA; CECÍLIO FILHO AB; CATELAN F; MARTINS MIEG. 2005b. Análise econômica de consórcios de alface americana x rabanete: um estudo de caso. Horticultura Brasileira 23: 853-858.

REZENDE BLA; CECÍLIO FILHO AB; MARTINS MIEG; COSTA CC. 2005c Custo de produção e rentabilidade da alface crespa, em ambiente protegido, em cultivo solteiro e consorciado com tomateiro. Informações Econômicas 35: 42-50.

SINOQUET H; CALDWELL RM. 1995. Estimation of light capture and partitioning in intercropping systems. In: SINOQUET H; CRUZ P. (Eds). Ecophysiology of tropical intercropping. Paris: INRA. p. 79-98.

SOUZA JL; RESENDE P. 2003. Rotação, sucessão e consorciação de culturas. In: ___________._. Manual de horticultura orgânica. Viçosa: Aprenda fácil. p.175-179.

TRANI PE; NAGAI H; PASSOS FA. 1997a. Tomateiro. In: RAIJ B; CANTARELLA H; QUAGGIO JA; FURLANI AMC. Recomendações de adubação e calagem para o estado de São Paulo. Campinas: IAC. p. 184.

TRANI PE; PASSOS FA; AZEVEDO FILHO JA. 1997b. Alface, almeirão, chicória, escarola, rúcula e agrião d’agua. In.: RAIJ B; CANTARELLA H; QUAGGIO, JA; FURLANI AMC. Recomendações de adubação e calagem para o estado de São Paulo. Campinas: IAC. p. 168-169.

TRENBATH BR. 1976. Plant interactions in mixed crop communities. In: PAPENDICK RI; SANCHES PA; TRIPLE GB. (Ed). Multiple cropping. Wisconsin: American Society of Agronomy. p. 129-160.

TRENBATH BR. 1986. Resource use by intercrops. In: FRANCIS CA. Multiple cropping systems. New York: Macmillan Publishing Company. p. 57-81.

WILLEY RW. 1979. Intercropping - its importance and research needs. Part 1 Competition and yield advantage. Field Crops Abstracts 32: 1-10. 